\title{
Predicting marital satisfaction from behavior: Do all roads really lead to Rome?
}

\author{
DEBRA S. GILL, ${ }^{a}$ ANDREW CHRISTENSEN,${ }^{a}$ AND \\ FRANK D. FINCHAM ${ }^{b}$ \\ ${ }^{a}$ University of California, Los Angeles; and ${ }^{b}$ University of Wales, Cardiff
}

\begin{abstract}
The concurrent and longitudinal associations between spousal communication and marital satisfaction were investigated using two systems of observation (rating and coding) and two statistical methods. A coding system and a rating system were used to assess the amount of positive, negative, and avoidant behavior exhibited by 30 couples engaged in a 15-minute discussion about a marital problem. Change scores as well as regression methods were used to calculate correlations between communication behaviors and one-year change in Marital Adjustment Test (MAT) scores. Positive behavior by both spouses predicted an increase in wives' satisfaction, and negative behavior by both spouses predicted a decrease in wives' satisfaction. None of the variables consistently predicted changes in husbands' satisfaction. The two systems of observation and the two methods of analysis produced similar though not identical results. The article discusses the constructs of negative and avoidant behavior, reviews limitations of standard marital research methods, and offers theoretical and methodological recommendations for future research.
\end{abstract}

\section{Competing Models of Marriage}

Social learning models of marriage suggest that marital satisfaction will decline to the extent that spouses respond to conflict with negative communication and fail to engage in constructive problem solving. When conflicts are confronted with criticism, blame, and contempt, practical problems or differences in perspective tend to escalate into personalized battles that make the marriage aversive to both spouses. Conversely, spouses who engage in positive communication, such as acknowledgment, empathy,

Debra S. Gill and Andrew Christensen, Department of Psychology, University of California, Los Angeles (UCLA); Frank Fincham, School of Psychology, University of Wales.

Correspondence concerning this article should be addressed to Debra Gill, PhD, Department of Epidemiology and Public Health, Health Behavior Unit, University College London, 2-16 Torrington Place, London WC1E 6BT, UK. E-mail: dsgill@mail. med.upenn.edu. and problem solving, are expected to find their marriages rewarding and to move forward in spite of conflict (Jacobson \& Margolin, 1979; Jacobson, Waldron, \& Moore, 1980; Smith, Vivian, \& O'Leary, 1990; Stuart, 1980).

In contrast to the social learning approach, some authors have advanced what might be termed a negative confrontation model of marital interaction. For example, Gottman and Krokoff (1989) hypothesize that spouses" "conflict engagement" in general, and wives' anger in particular, may lead to long-term improvements in marital satisfaction for one or both partners. They reasoned that confrontation of marital problems, while unpleasant in the short term, is an essential step toward resolving problems and achieving long-term marital harmony. Gottman and Krokoff (1989) suggest that wives who want to maximize longterm marital satisfaction should be less concerned with being compliant and positive 
and more concerned with "getting their husbands to confront areas of disagreement and to openly vent disagreement and anger" (p. 52).

Recent support for this suggestion was provided by Karney and Bradbury (1997), who utilized hierarchical linear modeling to assess the impact of behavior on the trajectory of marital change. They found that wives' more negative behavior predicted less rapid declines in spouses' marital satisfaction over the first 4 years of marriage (controlling for the association between wives' behavior and the spouses' baseline satisfaction). These researchers speculated that wives' blaming and criticism during a problem-solving discussion might represent a strong commitment to the relationship that, in the long run, is more important to the health of the marriage than the quality of their problem-solving communication.

Which model yields a more accurate portrayal of the longitudinal course of marriage? Existing research provides contradictory evidence (Bradbury \& Karney, 1993). Christensen and colleagues found that composite scales of Demand and of Negativity (encompassing blame, pressure for change, anger, frustration, hostility, sadness, hurt, interrupting, and dominating) were related positively to change in marital satisfaction measured 12 months after baseline (Heavey, Christensen, \& Malamuth, 1995; Heavey, Layne, \& Christensen, 1993). Similarly, as mentioned above, Gottman and Krokoff (1989) found that disagreements and anger exchanges were related positively to change in marital satisfaction after 36 months. Likewise, Karney and Bradbury (1997) found that wives' negativity was associated with a positive marital trajectory. These studies support a negative confrontation model of marital interaction.

Other findings support the social learning model. Julien, Markman, and Lindahl (1989) found that negative escalation in problem-solving discussions predicted declines in marital satisfaction across 18-, 36-, and 48-month follow-up assessments. Likewise, Noller and colleagues found that negative communication behaviors such as coercion, manipulation, and demand- ingness predicted declines in wives' marital satisfaction over a 2-year period (Noller, Feeney, Bonnell, \& Callan, 1994). Filsinger and Thoma (1988) reported post hoc results showing that females' interruptions during interaction before marriage predicted declines in both partners' satisfaction over 60 months, and Huston and Vangelisti (1991) reported that declines in wives' satisfaction over 24 months were predicted by both spouses' negativity as assessed from a series of telephone interviews. Additionally, research on marital dissolution suggests that mutually hostile behavior (Katz \& Gottman, 1993) and contempt and criticism (Gottman, 1993) predict divorce.

Both models also received some support when positive communication was used as a predictor. Gottman and Krokoff (1989) found that positive verbal communication during a problem-solving discussion-including agreement, approval, and humorwas positively correlated with baseline marital satisfaction but negatively correlated with change in satisfaction after 36 months. This result was interpreted as supporting their negative confrontation model. Conversely, Julien and colleagues (1989) found that positive escalation observed in a laboratory problem-solving discussion predicted higher levels of marital satisfaction over 36 and 48 months; likewise, Filsinger and Thoma (1988) reported that males' positive reciprocity before marriage predicted higher levels of females' satisfaction 60 months later. In contrast to all these studies, Huston and Vangelisti (1991) found no association between affectionate expression and later marital satisfaction after controlling for initial marital satisfaction.

\section{The Role of Avoidance}

In addition to negativity and positivity, avoidance and withdrawal in spousal interaction have been studied. According to the negative confrontation model, withdrawal from communication prevents airing of feelings and thoughts surrounding a problem, and therefore impedes a couple's movement toward resolution. As a result, problems in a relationship are likely to per- 
sist and intensify, leading to declines in marital satisfaction (Gottman and Krokoff, 1989). In the social learning model, the predicted impact of avoidance is less clear-cut, and it depends upon the nature of the discussions that are being avoided. If avoidance reduces the frequency of discussions that involve blame and criticism, it may positively influence a marriage. However, if avoidance reduces the frequency of productive communication about problems, then it may be bad for marriages (Jacobson, 1989; Stuart, 1980). The difference between the two models is that the negative confrontation model places less emphasis than does the social learning model on the detrimental effects of negative emotions (e.g., anger) and behaviors (e.g., criticism, violence) that could emerge in a problem-focused discussion. It is important to acknowledge that avoidance typically occurs within a communication system such that avoidance by one spouse often co-occurs with either parallel avoidance (Christensen \& Pasch, 1993; Jacobson, 1989) or demandingness (Christensen \& Heavey, 1990) by the other spouse, resulting in a relationship that fails to reward either spouse very well.

Results of research on avoidance have been mixed. Heavey and co-workers (1993) found no relationships between observed withdrawal behaviors and longitudinal marital satisfaction over 12 months when withdrawal was analyzed separately from the demanding behavior of the partner. However, Heavey and colleagues (1995) found that husbands' avoidance predicted decline in wives' marital satisfaction at 30 month follow-up. Similarly, Smith et al. (1990) found that affective disengagement (silence and quietness during interaction) before marriage was associated with lower levels of marital satisfaction measured 18 and 30 months after marriage. In other words, the happier couples at these followup assessments were those who initially engaged in active communication about problems.

Contradictory results on the link between conflict avoidance and marital satisfaction may represent differences in the role of avoidance between different subgroups of couples. For example, in their observational research, Raush, Barry, Hertel, and Swain (1974) found a subgroup of highly satisfied but avoidant couples and suggested that the impact of avoidance may depend upon the relationship context. In particular, "when there was a bond of mutual affection between partners, then ... avoidance could coexist with happy marriages" (p. 204). Similarly, Smith and colleagues (1990) found a statistical interaction between disengagement and positivity that implied that the impact of disengagement depends on the level of positivity existing in the marriage. The authors conclude that "high levels of Positivity coupled with high levels of Disengagement bode well for the relationships" (p. 796).

Not only is relationship context important, but the content of what is avoided is also important. It may be helpful for couples to avoid talking about problems for which there is no solution. Conversely, avoidance of issues that could be solved interferes with daily functioning and would be detrimental for couples. Furthermore, the avoidance of problem-solving communication may be quite different from the avoidance of intimate communication and may have quite different effects on satisfaction.

Finally, the assessment of avoidance through laboratory problem-solving discussions presents some serious limitations. First, couples are usually given the opportunity to reject topics they do not wish to discuss under observation. Thus, the topics leading to most avoidance may never appear in a laboratory discussion. Second, demand characteristics of the situation prevent avoidance. Having agreed to discuss a topic, no member of a couple could easily leave the room or refuse to talk about the topic further, even though he or she might do so in the home setting.

Therefore, research on observational measurement of avoidance needs to be buttressed by self-report measurements. For example, using the Communication Patterns Questionnaire (Christensen \& Sullaway, 1984), Rankin-Esquer and colleagues (1998) identified a group of distressed couples who scored in the non- 
distressed range on "Mutual Constructive Communication" (a measure of positivity minus negativity in communication) but who had high scores on "Mutual Avoidance and Withholding." Both measures referred to problem-solving discussions. Apparently, these couples maintained their positive communication only by avoiding conflictual topics, and presumably they suffered in relationship satisfaction as a result.

\section{Differences in Measurement}

As with avoidance, interpretation of other contradictory findings in the marital literature is complicated by differences in measurement of key constructs. Some differences lie in whether observational versus self-report measurement was used. For example, self-reported avoidance may reflect different dynamics and produce different results than avoidance observed in a laboratory. But even across observational systems, there are differences in how constructs are defined and in which behaviors are integrated into assessments. For example, some systems might include only verbal behavior, and others only nonverbal, whereas some systems may incorporate both.

Two general types of observational procedures have been used to categorize and quantify marital communication: coding systems and rating systems. Coding systems generally break communication down into discrete units (such as speaking turns, or distinct facial expressions) and each of these units is classified or "coded" as representing one specific category of behavior from a list of possible categories that the coders are trained to identify. Scale scores are determined by tallying the number of times each code is used for each partner. Rating systems, in contrast, do not ask observers to assign a single categorical label to a given unit of behavior. Rather, for each observed segment of interaction (which is typically delineated in units of time like 5 minutes or 15 minutes), raters make a series of Likert-scale ratings on a number of different categories. The idea is for trained observers to gain a comprehensive picture of a spouse's communication patterns by inte- grating the frequency, intensity, and context of communication behaviors, and then to indicate the relative presence or absence of each type of communication observed in the interaction. (See Table 1 for summary of differences.)

Contradictory results across studies could reflect differences in observational methodology, though it is difficult to distinguish the impact of observational methodologies from real differences between the groups of participants who were observed. It is not difficult to generate examples of how the same interaction could produce different results depending upon which observational system was used. For instance, if a person held his or her partner's hand when delivering critical feedback and seemed to have beneficent intentions, an observer using an integrative rating system could count this criticism as only slightly negative, and could also use it to raise ratings of acceptance or positive behavior. However, an observer using a verbal coding system that reduces interactions to transcripts and tallies incidences to determine category scores would count a kindly delivered criticism the same as a criticism yelled in a harsh voice and intended to either hurt the partner, defend the self, or avoid the issue.

Both observational methods have advantages and disadvantages. For example, behavioral coding can be used to analyze sequences of interaction, whereas summary ratings cannot. Coding, however, takes more time to perform than does rating. Additionally, rating systems may produce more facevalid assessments of interaction because observers have the discretion to give different weights to different instances of a behavior based its intensity and the context in which it occurs (Christensen \& Arrington, 1987). Coding systems, in contrast, may yield greater reliability because all coders are trained to count events in the same way so that subjective judgment is minimized. The present study used both a coding system and a rating system to analyze the same set of taped interactions, and then examined whether results varied across systems. It was believed that agreement across systems for 
Table 1. Communication behaviors that comprise each composite scale within the Revised Conflict Rating Scale (RCRS) and the Verbal Tactics Coding Scheme (VTCS)

\begin{tabular}{|c|c|}
\hline \multicolumn{2}{|c|}{ Scales } \\
\hline $\begin{array}{l}\text { Revised Conflict Rating Scale } \\
\text { Behaviors (RCRS) }\end{array}$ & $\begin{array}{l}\text { Verbal Tactics Coding Scheme } \\
\text { Behaviors (VTCS) }\end{array}$ \\
\hline $\begin{array}{l}\text { Negative } \\
\text { Blames: blames, accuses, or criticizes } \\
\text { Pressures for Change: requests, demands, } \\
\text { nags, manipulates, or otherwise pressures } \\
\text { partner to change } \\
\text { Negative Judgments and Contempt: } \\
\text { communicates the belief that partner's views, } \\
\text { feelings, and behaviors are of poor quality, } \\
\text { subordinate to own views and feelings, } \\
\text { and unworthy of respect or serious } \\
\text { consideration. }\end{array}$ & $\begin{array}{l}7 \text { Distributive codes include: } \\
\text { Faulting, Rejection, Prescription, } \\
\text { Hostile Questioning, Hostile Joking, } \\
\text { Presumptive Attribution, } \\
\text { Avoiding Responsibility } \\
\text { These } 7 \text { codes tap the following areas: } \\
\text { - Blaming and criticizing } \\
\text {-Expressing hostility } \\
\text { - Pressuring for change in partner } \\
\text {-Denying personal responsibility }\end{array}$ \\
\hline $\begin{array}{l}\text { Positive } \\
\text { Positive Acceptance: listening to, } \\
\text { understanding, and accepting partner's views, } \\
\text { feelings, and behaviors. }\end{array}$ & $\begin{array}{l}9 \text { Integrative codes include: } \\
\text { Description, Disclosure, Qualification, } \\
\text { Soliciting Disclosure, Negative Inquiry, } \\
\text { Problem Solving, Empathy/Support, } \\
\text { Emphasizing Commonalties, Responsibility } \\
\text { These } 9 \text { codes tap the following areas: } \\
\text { - Giving and soliciting information } \\
\text { - Initiation of Mutual Problem Solving } \\
\text {-Supporting Partner and Relationship }\end{array}$ \\
\hline $\begin{array}{l}\text { Avoidant } \\
\text { Withdraws: withdraws, become silent or refuses } \\
\text { to discuss a topic. } \\
\text { Avoids: actively avoids discussion by } \\
\text { hesitating, changing topics, diverting } \\
\text { attention, or delaying. } \\
\text { Fails to Engage: This is the reverse (negative) } \\
\text { of the rating for Discussion: tries to discuss } \\
\text { the problem; is engaged and involved in the } \\
\text { topic at hand. }\end{array}$ & $\begin{array}{l}11 \text { Avoidance codes include: } \\
\text { Simple Denial, Extended Denial, } \\
\text { Ambivalence, Topic Shifting, Topic } \\
\text { Avoidance, Underresponsiveness, } \\
\text { Semantic Focus, Process Focus, Pessimism } \\
\text { These } 11 \text { codes tap the following: } \\
\text { - Denial or ambivalence about existence } \\
\text { or severity of problem } \\
\text { - Terminating, limiting or supplanting } \\
\text { discussion of problem through } \\
\text { various strategies including changing } \\
\text { topics, focusing on process, joking } \\
\text { and using abstraction }\end{array}$ \\
\hline
\end{tabular}

certain results would justify greater confidence in those results.

\section{Different Statistical Procedures}

Another methodology that has varied across previous research is statistical procedure. Two alternative statistical techniques have been used to analyze change in marital satisfaction: the change-score approach and the partial correlation, or regressed- change approach. With the change-score approach, the dependent variable is computed as the difference between Time 2 and Time 1 marital satisfaction scores, and the hypothesized predictor variable is correlated with this value (e.g., Gottman \& Krokoff, 1989). With the regressed-change (or partial correlation) approach, Time 1 marital satisfaction is controlled for by partialing out Time 1 marital satisfaction scores (from both Time 2 satisfaction and from the 
behavioral predictor) before a correlation is computed between Time 2 satisfaction and the predictor. Several investigators have criticized the change-score approach, saying it is likely to yield artifactual results driven by regression to the mean (e.g., Smith, Vivian, \& O'Leary, 1991; Woody \& Costanzo, 1990).

However, others have defended the change-score approach and argued that the regressed-change approach produces similar problems within certain types of data sets, but that many data sets are robust to these problems and can yield reliable results with both these methods (e.g., Gottman \& Krokoff, 1990). Still others have argued that neither method is optimal for assessing change, and have demonstrated with computer simulations that problems are somewhat inconsistent and highly dependent on variance and correlational characteristics of different samples (Bradbury \& Karney, 1996; Karney \& Bradbury, 1995). In light of this controversy, it seems reasonable that convergence of results produced by the change-score and regressed-change methods might justify increased confidence in these results. The current study used both methods of statistical analysis and evaluated results in terms of convergence between these two methods.

\section{Study Hypotheses}

Predictions in this article were guided by the social learning model because the weight of evidence seems to support this model (e.g., Filsinger \& Thoma, 1988; Huston \& Vangelisti, 1991; Julien et al., 1989; Katz \& Gottman, 1993). Accordingly, we hypothesized that (a) negativity by either spouse would predict declines in marital satisfaction for both partners, (b) positivity by either spouse would predict improvements in marital satisfaction for both partners, and (c) avoidance of discussion by either spouse would predict no consistent effect on marital satisfaction because the sample contained various subgroups for whom avoidance would have differing implications.

\section{Method}

\section{Participants}

Forty couples participated in the Time 1 laboratory component of the study. ${ }^{1}$ To sample couples across a broad range of marital satisfaction levels, 29 of the 40 couples were recruited through advertisements in local newspapers, and 11 were recruited from a local clinic they had contacted to investigate the possibility of marital therapy.

Twelve months later, we attempted to recontact the 40 couples. Thirty of the couples ( $75 \%$; 7 clinic recruited and 23 community recruited couples) returned the Time 2 materials via mail. These couples did not differ significantly in Time 1 marital satisfaction or demographic variables from the couples who did not complete Time 2 data. The present analysis involves the 30 couples who completed data at Time 1 and Time 2. Although at both time points clinic-recruited couples had lower marital satisfaction $(M=$ 85.6 and 90.6 for Time 1 and Time 2, respectively) than did couples recruited from the community $(M=100.2$ and 101.3 for Time 1 and Time 2 , respectively), $t$-tests showed that the differences were not statistically significant $(t(58)=1.4$ and 1.9 for Time 1 and Time 2, respectively).

There were also no differences between clinic and community couples on any of the demographic variables. At Time 1 these 30 couples had been married an average of 6.7 years $(S D=6.9)$, had an average of 1.6 children (mode $=1$ ), and had an average household income of $\$ 22,500$. Husbands averaged 14.7 years of education $(S D=2.4)$ and 31.2 years of age $(S D=7.1)$, and wives averaged 14.2 years of education $(S D=$ $2.1)$ and 30.2 years of age $(S D=7.0)$.

\section{Procedure and questionnaires}

At Time 1, couples arriving at the laboratory were separated and asked to complete

1. Prior analyses of these couples' interactions, using only the VTCS system and addressing different hypotheses, can be found in Bradbury, Campbell, and Fincham (1995) and Bradbury and Fincham (1991). 
a consent form, a demographics questionnaire, and the Marital Adjustment Test (MAT; Locke \& Wallace, 1959). The MAT is a widely used measure of marital satisfaction that yields a score ranging from 2 to 158. It has adequate reliability (split-half $r$ $=90$ ), and scores on this instrument correlate with clinicians' judgments of marital discord (Crowther, 1985). Spouses scoring above 100 on the MAT are commonly viewed as functioning in the nondistressed range, whereas those scoring below 100 are typically viewed as maritally distressed.

After completing the Time 1 MAT, couples completed an Inventory of Marital Problems (Geiss \& O'Leary, 1981). The Inventory of Marital Problems required spouses to rate on 11-point scales the extent to which each of 19 common marital problems was a source of difficulty or disagreement in their marriage. The experimenter summed the husbands' and wives' independent severity ratings of each marital problem and chose the problem with the highest summed score for the couple to discuss. If either spouse objected to discussing the selected problem, the issue with the next highest score was discussed.

The spouses were reunited, seated facing one another, and instructed to "try to work toward a mutually agreeable solution" to the selected problem for 15 minutes. The experimenter left the room, prepared the cameras and videocassette recorder for taping, and signaled the couples to begin their discussion. The couples were signaled to end their discussion after 15 minutes had elapsed. Couples were then debriefed and paid $\$ 30$ for their participation. Approximately 12 months later, the MAT was mailed to all couples who could be contacted by telephone, along with instructions to complete the form independently without consulting their partner. Couples were paid $\$ 20$ for participating at Time 2 .

\section{Observational methods}

The Revised Conflict Rating Scale (RCRS) was selected for global ratings because its parent scale, the Conflict Rating Scale
(CRS), has been widely used in marital research. The RCRS was based on the Conflict Rating Scale, used by Christensen and Heavey (1990) and expanded by Heavey et al. (1993). Seven of the 25 behavioral categories rated in this Revised Conflict Rating Scale (RCRS) were utilized in this study because they represented one of the three general classes of behavior we were interested in: negative, positive, and avoidant. Table 1 provides a brief description of the behaviors used to index negative, positive, and avoidant behavior within each of the two coding systems used in the current investigation.

Procedure for RCRS observations. Videotapes of the couples' discussions were rated using the RCRS by eight undergraduate observers who were blind to the hypotheses of the study. Before making their ratings, observers were trained for 8 hours over a 2week period on all the RCRS behavioral categories. The rating period began when the observers had achieved a high level of agreement with one another and with predetermined criterion ratings for sample interactions. Team meetings were held each week throughout the 6-week rating period where observers' ratings were compared and discussed. This was done to maintain high interrater reliability and reduce observer drift away from predetermined RCRS scale meanings. The meaning of each scale was standardized, and raters were encouraged to take notes on observations that justified their ratings of target spouses on various scales. The raters were also encouraged to incorporate their judgments of the strength of various communication acts as well as of the target's multiple meanings and intentions when determining how much each act should load on a given rating scale.

Two teams, each consisting of four independent observers, alternated between rating the husband and the wife in each discussion; each observer thus rated 40 spouses, one spouse per couple. Ratings were based on the entire 15-minute interaction. Each spouse thus received four ratings, one from each member of a team, for each of the 
seven RCRS behavioral categories comprising the three summary scales of Negative, Positive, and Avoidant behavior. The ratings by the four observers (made on a 1-to-9 Likert scale) were averaged to obtain a single mean in each of the seven behavioral categories for each spouse. These seven mean ratings were then summed to form the composite scales of Negativity, Positivity, and Avoidance as described above.

Effective reliabilities (using SpearmanBrown formula; Rosenthal, 1982) were between .85 and .95 for all seven subscales that comprised the three composite scales. Internal consistency alphas were .90 for Husband Negativity, .88 for Wife Negativity, .80 for Husband Avoidance, and .73 for Wife Avoidance. Because the Positivity scale consisted of only one rating category, there is no internal consistency alpha for Husband or Wife Positivity.

The Verbal Tactics Coding Scheme (VTCS; Sillars, 1981) was selected to represent the microlevel coding systems because it provides reliably measured comprehensive coverage of negative, positive, and avoidant communication behaviors (Bradbury \& Fincham, 1992; Cohan \& Bradbury, 1997; Sillars, Pike, Jones, \& Murphy, 1984). Although not as labor-intensive as many of the microlevel coding systems used in the marital field, the VTCS required more time and effort than did the RCRS to code interactions because each speaking turn, rather than the entire interaction, required a judgment to be made about code assignment. It took approximately 15 hours of training to achieve a satisfactory level of agreement between coders. In Sillar's original VTCS, negative behaviors were called "distributive" acts and positive behaviors were called "integrative" acts. We call the summary scales positive, negative, and avoidant for simplicity, but recognize that these names may not reflect certain nuances of the original constructs. As indicated in Table 1 , the 27 behavioral codes from the VTCS were combined into three composite scales as recommended by Sillars (1981). The content descriptions provided below the list of codes were written by the first author of this article in an attempt to efficiently summarize and clarify the content of the VTCS scales for the reader.

Procedures for VTCS observations. Verbatim transcripts of the interactions were prepared. Two trained coders blind to the hypotheses of this study used both the transcripts and videotapes to demarcate speaking turns and then to assign one of 27 VTCS codes to each speaking turn (Sillars, 1981). Sillars's notes explain that, with a few exceptions, codes were designed to enable relatively objective categorization of each utterance on the basis of outward features, and to minimize the need for coders to interpret the speaker's message or to make inferences about the speaker's intent. Independent coding of $20 \%$ of the videotapes revealed that coders were reliable (coefficient kappa $=.84$ ).

Differences between observational systems. Although the three classes of communication assessed by RCRS and VTCS are similar, there are important differences between these observational methodologies that generally reflect differences between global rating and microlevel coding systems. Table 2 indicates primary differences between the VTCS and the RCRS in the following eight areas: material for analysis, units of analysis, number of behavioral categories, type of scales used, incorporation of frequency information, level of inference required, time required for training, time required for making ratings.

\section{Results}

\section{Mean ratings}

Marital satisfaction (MAT). Mean marital satisfaction scores changed minimally between Time 1 and Time 2, though some couples had large changes. The mean MAT score for husbands was $101.9(S D=20.7)$ at Time 1 and $100.9(S D=19.1)$ at Time $2(M$ change $=1.0)$. The mean MAT score for wives was $95.7(S D=28.8)$ at Time 1 and $93.0(S D=31.4)$ at Time $2(M$ change $=$ 
Table 2. Differences between rating and coding methods as represented by Revised Conflict Rating Scale (RCRS) versus Verbal Tactics Coding Scheme (VTCS)

\begin{tabular}{|c|c|c|}
\hline Area of Difference & $\begin{array}{l}\text { Coding System: VTCS-Verbal } \\
\text { Tactics Coding Scheme }\end{array}$ & $\begin{array}{l}\text { Rating System: RCRS-Revised } \\
\text { Conflict Rating Scale }\end{array}$ \\
\hline $\begin{array}{l}\text { Material used for } \\
\text { analysis: }\end{array}$ & $\begin{array}{l}\text { Verbal behavior only; } \\
\text { transcripts of interaction } \\
\text { are analyzed. }\end{array}$ & $\begin{array}{l}\text { Verbal and nonverbal } \\
\text { communication behavior }\end{array}$ \\
\hline Unit of analysis: & Discrete speaking turns & Entire 15-minute interaction \\
\hline $\begin{array}{l}\text { Number of } \\
\text { categories: }\end{array}$ & $\begin{array}{l}\text { More categories of behavior, } \\
\text { each more narrowly defined }\end{array}$ & $\begin{array}{l}\text { Fewer categories of behavior, } \\
\text { each more broadly defined }\end{array}$ \\
\hline Type of scale: & Ratio Scale ( 0 to total) & Likert Interval Scale (1-9) \\
\hline Impact of frequency: & $\begin{array}{l}\text { Scale scores determined by } \\
\text { counting frequency of each } \\
\text { behavior coded (adjusted for } \\
\text { total speaking turns) }\end{array}$ & $\begin{array}{l}\text { Scale scores determined by } \\
\text { integrating intensity, } \\
\text { frequency, and context } \\
\text { of behaviors }\end{array}$ \\
\hline Level of subjectivity: & Minimizes subjectivity & Encourages some subjectivity \\
\hline Time to train raters: & 15 hours & 8 hours \\
\hline Time to make ratings: & Several hours per couple & Less than one hour per couple \\
\hline
\end{tabular}

2.7). From Time 1 to Time 2, MAT scores increased for 11 of the husbands ( $M$ increase among these husbands $=15.9$, median $=7$, range $=1$ to 42 ) and decreased for 19 of the husbands ( $M$ decrease among these husbands $=10.9$, median $=8$, range $=1$ to 45 ). Over the same interval, MAT scores increased for 15 of the wives ( $M$ increase among these wives $=14.2$, median $=$ 11 , range $=1$ to 44$)$ and decreased for 15 of the wives ( $M$ decrease among these wives $=19.5$, median $=20$, range $=2$ to 49 ).

Preliminary analyses indicated that (a) Time 1 and Time 2 assessments of marital satisfaction were significantly correlated within each spouse (for husbands, $r(28)=$ $.61, p<.001$; for wives, $r(28)=.76, p<.001$ ); (b) husbands' and wives' marital satisfaction scores were marginally related to one another at Time $1, r(28)=.28, p<.07$ and significantly related at Time $2, r(28)=.42, p$ $<.01$; and (c) husbands' and wives' MAT change scores were not reliably associated.

Observations. Means of each observation category are presented in the top two rows of Table 3. Because we used two systems (VTCS and RCRS) to assess each of the three communication behaviors, there were six predictor variables for each spouse. Six two-tailed $t$-tests at an alpha of .05 con- firmed that husbands' and wives' mean scores did not significantly differ on any scale.

\section{Agreement between observational systems}

The top right quadrant of Table 3 shows the associations between scales of the two observational systems. The bold diagonal shows the agreement between the RCRS and VTCS data for like scales. Agreement is particularly high on the negativity and positivity dimensions such that negativity ratings for each system were strongly correlated with one another, as were positivity ratings. Avoidance ratings were somewhat less consistent across systems, though the moderate correlations were statistically significant for wives and almost significant for husbands $(p=.06)$. Furthermore, negativity and positivity ratings were inversely correlated across systems (e.g., RCRS negativity was negatively associated with VTCS positivity).

\section{Within-system associations among observed behavior}

The upper left and lower right quadrants of Table 3 show associations of scales within each observational system. Significant asso- 


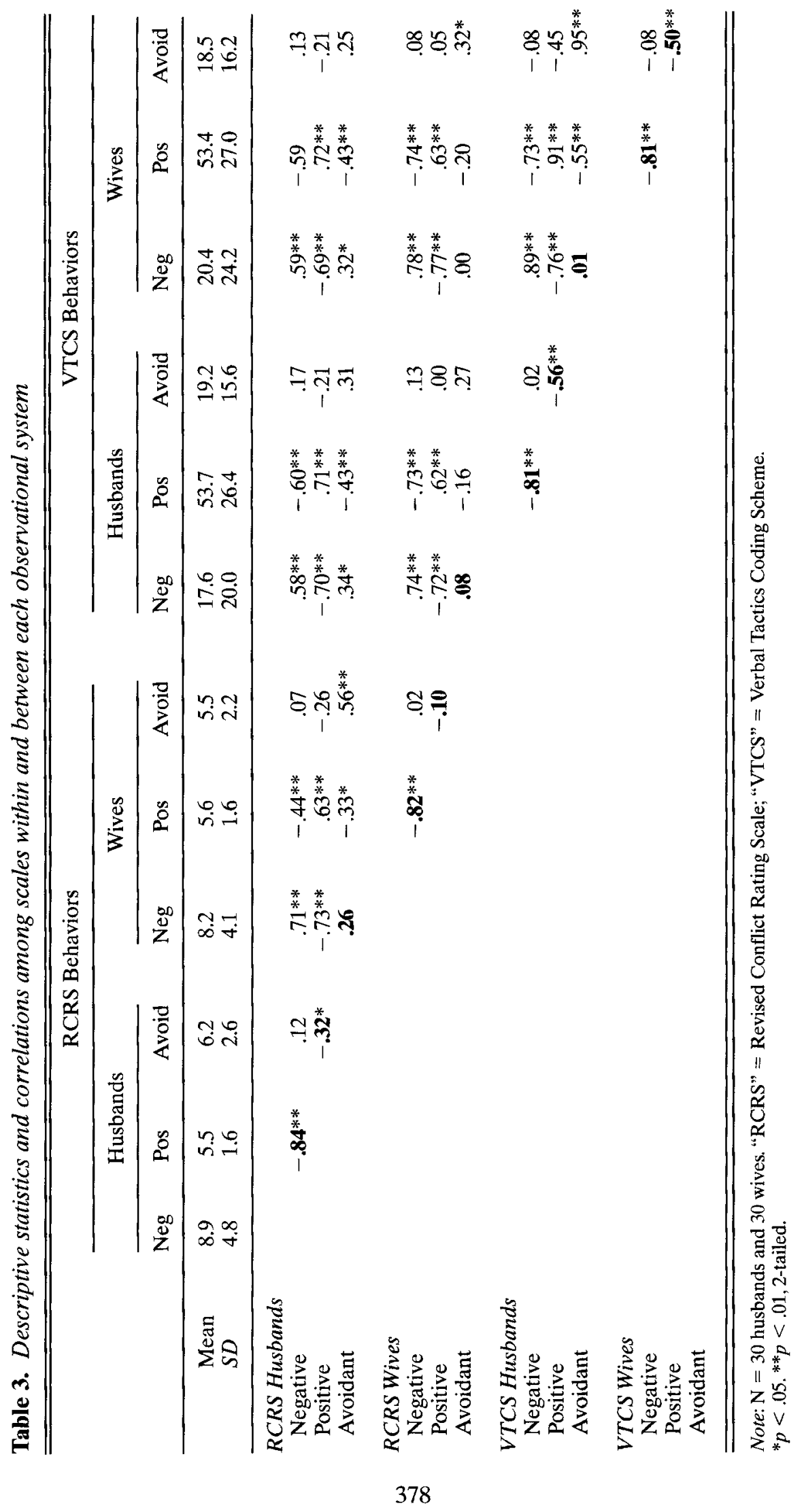


ciations existed between almost all positivity and negativity ratings both within and across spouses. Avoidance ratings were inconsistently correlated with positivity and negativity ratings.

\section{Concurrent associations between communication and satisfaction}

Concurrent associations between marital satisfaction and observational data were assessed by calculating simple Pearson correlation coefficients between each behavioral variable and Time 1 MAT for each spouse. Concurrent correlations between communication and marital satisfaction are shown in Table 4 for husbands and wives. Examining within-spouse associations, husbands' negativity (VTCS) was associated with lower husbands' satisfaction at Time 1, husbands' positivity (RCRS and VTCS) was associated with higher husband satisfaction at Time 1, and husbands' avoidance (RCRS) was associated with lower husband satisfaction at Time 1 . In contrast, wives negativity and wives' avoidance were not associated with wives' satisfaction at Time 1 , though wives' positivity (RCRS) was associated with higher wives' satisfaction.

Examining cross-spouse correlations, no type of husbands' communication was associated with wives' satisfaction at Time 1 . However, husbands' satisfaction at Time 1 was inversely associated with wives' avoidance (RCRS) and directly associated with wives' positivity (RCRS). In contrast, husbands' Time 1 satisfaction was not associated with wives' negativity.

\section{Longitudinal associations}

As outlined in the introduction, longitudinal prediction of marital satisfaction was assessed using both the change-score method

Table 4. Concurrent and longitudinal associations between behavior and marital satisfaction

\begin{tabular}{|c|c|c|c|c|c|c|}
\hline & \multicolumn{3}{|c|}{ Husbands' Satisfaction } & \multicolumn{3}{|c|}{ Wives' Satisfaction } \\
\hline & Concurrent & $\begin{array}{c}\text { Change } \\
\text { Score }\end{array}$ & $\begin{array}{c}\text { Regressed } \\
\text { Change }\end{array}$ & Concurrent & $\begin{array}{c}\text { Change } \\
\text { Score }\end{array}$ & $\begin{array}{c}\text { Regressed } \\
\text { Change }\end{array}$ \\
\hline \multicolumn{7}{|c|}{ Husbands' Behavior } \\
\hline \multicolumn{7}{|c|}{ Negative } \\
\hline RCRS & -.27 & .16 & .02 & -.14 & $-.36 *$ & $-.41 *$ \\
\hline VTCS & $-.41 *$ & .28 & -.09 & -.19 & -.27 & $-.33^{*}$ \\
\hline \multicolumn{7}{|l|}{ Positive } \\
\hline RCRS & $.43^{* *}$ & $-.33^{*}$ & -.13 & .28 & .27 & $.36^{*}$ \\
\hline VTCS & $.40^{*}$ & $-.35^{*}$ & -.18 & .16 & .28 & $.33 *$ \\
\hline \multicolumn{7}{|l|}{ Avoidant } \\
\hline RCRS & $-.45^{* *}$ & $.36^{*}$ & .17 & .23 & -.08 & -.08 \\
\hline VTCS & -.19 & .25 & .17 & -.02 & -.11 & -.10 \\
\hline \multicolumn{7}{|c|}{ Wives' Behavior } \\
\hline \multicolumn{7}{|c|}{ Negative } \\
\hline RCRS & -.28 & -.15 & -.00 & -.17 & $-.31 *$ & $-.37 *$ \\
\hline VTCS & -.19 & .05 & -.06 & -.09 & $-.39 *$ & $-.42 *$ \\
\hline \multicolumn{7}{|l|}{ Positive } \\
\hline RCRS & $.33^{*}$ & -.08 & .11 & $.39 *$ & $.35^{*}$ & $.49 * *$ \\
\hline VTCS & $.32 *$ & .15 & -.01 & .07 & $.34 *$ & $.37 *$ \\
\hline \multicolumn{7}{|l|}{ Avoidant } \\
\hline RCRS & $-.47 * *$ & $.55^{* *}$ & $.41 *$ & .10 & .10 & -.13 \\
\hline VTCS & -.18 & .18 & .11 & -.00 & -.07 & -.07 \\
\hline
\end{tabular}

Note: $\mathrm{N}=30$ husbands and 30 wives. "RCRS" = Revised Conflict Rating Scale; "VTCS" = Verbal Tactics Coding Scheme.

$* p<.05 . * * p<.01,2$-tailed. 
and the regressed-change (i.e.,partial correlation) method. Each longitudinal association between a spouse's Time 1 (baseline) behavior rating and a spouse's satisfaction at Time 2 (follow-up) was assessed using two types of correlation coefficients. One was a simple correlation between a Time 1 behavior rating and the MAT change score (where a decline in MAT was calculated as a negative value). The other was a partial correlation coefficient between Time 1 behavior rating and Time $2 \mathrm{MA} T$, controlling for Time 1 MAT. These two correlation coefficients were calculated within and between spouses for each of the three behavioral categories measured by each of the two observational systems. These longitudinal correlation coefficients are presented in Table 4 and described below.

Within-spouse correlations. Husbands' negativity predicted no changes in husbands' satisfaction, no matter which observational system or statistical method was used. Husbands' positivity was negatively associated with change in husbands' satisfaction using the change-score method (RCRS and VTCS) but not using the regressed-change method. Husbands' avoidance was positively associated with change in husbands' satisfaction using only the change-score method (RCRS).

In distinct contrast to husbands' data, wives' negativity was associated with declines in wives' satisfaction using both of the observational systems (RCRS and VTCS) and both of the statistical methods. Conversely, wives' positivity was associated with improvement in wives' satisfaction using both of the observational systems (RCRS and VTCS) and both of the statistical methods. Wives' avoidance, however, predicted no changes in wives' satisfaction at Time 2 .

Between-spouse correlations. Husbands' negativity predicted declines in wives' satisfaction using both the change-score method (RCRS) and the regressed-change method (RCRS and VTCS). Husbands' positivity predicted improvements in wives' satisfaction using only the regressed-change method (RCRS and VTCS). Husbands' avoidance did not predict changes in wives' satisfaction.

Wives' negativity did not reliably predict declines in husbands' satisfaction, and wives' positivity did not reliably predict improvements in husbands' satisfaction. Wives' avoidance (RCRS), however, predicted improvements in husbands' satisfaction using both the change-score and regressed-change method.

Agreement between the change-score and regressed-change methods. Agreement between the two statistical methods was substantial. Within all 24 pairs of correlations, results from the two methods were either both nonsignificant or both in the same direction. In 18 cases, the same result was produced by both statistical methods (in 6 pairs, both correlations were statistically significant and in the same direction, and in 12 pairs both correlations were nonsignificant). In the remaining 6 cases, the two methods produced different results (correlations were in same direction, but only one was statistically significant). Disagreement between statistical methods was observed only when husbands' negativity (RCRS and VTCS) and husbands' avoidance (RCRS) were tested as predictors of spousal satisfaction.

\section{Discussion}

One goal of this study was to examine predictive relationships between spousal communication and changes in marital satisfaction in order to compare evidence for two competing theories. Additionally, in view of mixed evidence, and of methodological variation among prior studies, the current study was designed to examine these predictive relationships using two observational systems-rating and coding-and two statistical approaches-regressed change and change scores. Because this study directly compares results achieved by different methods applied to the same data set, it sheds light on the ways in which 
methodological differences might moderate study outcomes.

\section{Theoretical issues}

On the whole, our results tend to support a social learning perspective on the association between problem-focused communication behaviors and longitudinal marital satisfaction for wives. Aversive communication generally predicted declines in satisfaction, whereas positive communication tended to predict improvements in satisfaction. These findings did not support the confrontational hypothesis (Gottman \& Krokoff, 1989) that negative communication benefits a marriage in the long run. Findings for avoidance were not clear in either direction and did not lend much support to either theoretical perspective.

Examining results more specifically, social learning theory suggests that each spouse's negative communication predicts declines in marital satisfaction for both partners. Partial support for this hypothesis was found in that both husbands' negativity and wives' negativity predicted declines in wives' satisfaction. No evidence was found to support Gottman and Krokoff's (1989) suggestion that conflict engagement characterized by disagreement and criticism contributes to longitudinal gains in satisfaction. Our results suggest, conversely, that when problems are confronted with blame, pressure, and negative judgments, marriages tend to deteriorate, at least from the wives' perspective.

Social learning theory also suggests that each spouse's positivity predicts improvements in marital satisfaction for both spouses. Again, support for this hypothesis was found only with respect to wives' marital quality. Wives' positive communication and husbands' positive communication predicted improvements in wives' satisfaction; however, neither spouses' positivity predicted improvements in husbands' satisfaction.

Associations between positivity and husband satisfaction were difficult to explain from either theoretical perspective. Using the regressed-change method, husbands' positivity and husbands' satisfaction were highly positively associated at Time 1 but negatively associated at Time 2 . We suspect this sign reversal reflects a statistical artifact stemming from a reduction in the correlation between positivity and satisfaction for husbands over time, rather than the development of an opposite relationship (see Bradbury \& Karney, 1993; Bradbury \& Karney, 1996; Rogossa, 1988; Woody \& Costanzo, 1990).

Differences between findings for husbands and wives warrant comment. Previous researchers have also reported more robust predictions for wives' satisfaction (Heavey et al., 1995). In the current data set, this is most likely due to the larger median changes in wives' MAT (median changes $=11+, 20-$ ) versus husbands' MAT (median changes $=7+, 8-$ ) from Time 1 to Time 2. Greater variance in the criterion variable (delta MAT) allows for larger correlation coefficients.

Finally, social learning theory provides no consistent prediction for the effect of avoidance on marital satisfaction because avoidance of problem-focused discussion has different effects in different marital contexts. Negative confrontation theory predicts that avoidance of problem-focused discussion would be bad for marriages in the long run. Results using the RCRS system did not support predictions of the confrontation model. Wives' avoidance was instead related to improvement in marital satisfaction for husbands, although baseline correlations revealed that the most dissatisfied husbands at Time 1 were those with highly avoidant wives.

The discrepancy between these Time 1 and Time 2 findings precludes any simple theoretical explanation. A potential explanation may be that the problems facing some couples at Time 1 were not ones resolvable by discussion, but rather problems that would resolve themselves over time (e.g., a layoff from a job). In this case, avoidance of discussion would prevent spouses from hurting one another with negative 
communication during stressful times. As discussed above, it is also quite likely that this sign reversal reflects a reduction in the initially strong correlation between avoidance and husband satisfaction rather than the development of an opposite association over time (Bradbury \& Karney, 1993; Woody \& Costanzo, 1990). It is clear from this study and from previous reports that the role of avoidance in marriage depends upon a number of moderating variables and calls for more complex theoretical development.

\section{Methodological issues}

Overall, results indicated high levels of agreement between the RCRS rating system and the VTCS coding system, particularly for negativity and positivity ratings. Smaller associations between these observational systems on avoidance ratings suggest that the coding of avoidance is more sensitive to methodological differences than is the coding of positive or negative behavior. More specifically, while the basic concept of avoidance seemed similar in both the RCRS and VTCS systems, operational definitions of avoidance differed sufficiently to result in somewhat different constructs being measured. The VTCS codes chosen for this study operationalized avoidance by counting the number of times subjects verbalized denial or ambivalence about the severity of the problem, or limited discussion through strategies such as changing topics, focusing on process, joking, or using abstraction. The RCRS rating of avoidance incorporated many of these same behaviors but its scope was broader. The RCRS ratings also included nonverbal signs of withdrawal (e.g., silence and looking away), indicators of low engagement in the discussion (e.g., low energy, low affect) and contextual factors that moderate the impact of avoidance. The operational differences between RCRS and VTCS methods of measuring avoidance may help explain why the correlations between avoidance scores produced by these two systems were only moderate. The broader scope of the RCRS system might explain why some findings were limited to data from this method: that is, when avoidance was present, it was more likely to be identified.

In contrast, some may consider this breadth to be a drawback in formulating specific theories about certain avoidance strategies and their impact on marital satisfaction. More refined assessment of different avoidance strategies would be valuable, but would require a different research design than that used in the current study. For example, it would likely require a more naturalistic observation protocol with fewer demand characteristics urging participation in discussion.

Given the current design, no matter which observational system is chosen, the demand characteristics of laboratory problem-solving discussions are likely to lead to underestimates of the use of avoidance strategies at home. It is unlikely that self-selected participants in this type of study would completely avoid discussing the topic that they themselves chose as acceptable, even if these spouses regularly avoid such discussion at home.

Researchers who wish to measure avoidance and its effects on marriage should carefully consider how they measure and operationalize avoidance, and in what context avoidance occurs. For example, self-report measures might produce a different picture from observational measures because they are less susceptible to demand characteristics of laboratory participation, they incorporate spouses' thresholds for perceiving avoidance, and they measure avoidance of issues and feelings that were not selected by spouses for laboratory discussion. The current study showed that even two observational systems can provide divergent results; for instance, the VTCS did not corroborate the finding produced by RCRS that wives' avoidance predicts improvement in husbands' satisfaction.

Statistical methodology. The two statistical methods produced the same results in 18 of 
24 cases $(75 \%)$, and results were in the same direction in all 24 cases. This agreement supports the view advanced by Gottman and Krokoff (1989) that changescore and regressed-changed methods tend to produce similar patterns of results. However, some differences existed in whether a given correlation reached statistical significance, indicating that the two methods can yield different results and potentially lead to divergent conclusions under some circumstances.

The two statistical methods utilized in this study were selected so as to aid interpretation of many prior studies that have used these methods. However, a newer statistical approach, hierarchical linear modeling (HLM, or more broadly, growth curve analysis) is worth mentioning as an alternative for future studies because it has a number of advantages when multiple waves of data are considered within a single investigation (see Rogossa, 1988, and Byrk \& Raudenbush, 1992, for explanations, and see Karney \& Bradbury, 1997, for an excellent example of HLM used to analyze marital change across eight waves of satisfaction data). For example, HLM can separate the effects of predictor variables (such as communication behaviors) on baseline satisfaction (the intercept of the growth curve) from their effects on the direction and rate of change in marital satisfaction (the slope of the growth curve). Applying HLM to the current sample may or may not produce the same results as were found using the change-score and regressed-changed approach. Future studies that directly compared results using the newer HLM approach and these more traditional methods would be instructive.

A number of results reached significance by both methods, and they may therefore warrant more confidence. For example, both methods found that negativity by either spouse predicted declines in wives' satisfaction and no changes in husbands' satisfaction. In contrast, one might place less confidence in findings that were statistically significant with only one of the methods--for example, that husbands' pos- itivity predicted declines in husbands' satisfaction and improvements in wives' satisfaction. A recent report by Karney and Bradbury (1997) provided a similar demonstration that important discrepancies can be found between two statistical methods testing the same conceptual question. In that study, when change scores were used, correlations between Time 1 marital satisfaction and change in satisfaction from Time 1 to Time 8 were negative. However, when HLM was used, correlations between the intercept and the slope of marital satisfaction were positive. Such findings of discrepant results across different statistical methods should engender caution in drawing theoretical conclusions from the results of any single study utilizing a single method. It should also remind us that the choice of a particular statistical method can have a fairly substantial impact on our results.

Finally, both of the statistical methods seemed susceptible to the problem of artifactual sign reversals between Time 1 and Time 2 correlations, though, as suggested by Woody and Costanzo (1990), this problem was more frequent when using the change-score method (five of the six reversals occurred using change scores). The present data suggest, however, that these reversals do not occur systematically, even using change scores, and that they occur less often than suggested by Woody and Costanzo (1990). In the present study, the likelihood of sign reversals increased with increasing magnitude of the Time 1 zero-order correlations. Our results are consistent with findings of a simulation study presented by Bradbury and Karney (1996).

\section{Study Limitations}

The current study had a number of limitations. First, the sample as a whole had a high level of stability in marital satisfaction scores from Time 1 to Time 2, which limited the size of effects. This stability may reflect the relatively long average marital length (6.7 years) of this sample in contrast with 
samples of newlyweds. Second, the sample was small, which prevented some more complex analyses (such as multiple regressions) and allowed results to be influenced heavily by data from a few spouses with large changes in marital satisfaction (e.g., four husbands and four wives had MAT changes more than 30 points).

Third, the sample was heterogeneous in terms of initial marital satisfaction, which complicates interpretation of results. For instance, a 20-point change in MAT may mean different things depending on the level of initial satisfaction. For a couple who was already at the low end of marital satisfaction, Time 1 behavior reflects an already unsatisfactory marriage, and a decline in MAT reflects a continuation of this downward trend. But, for a couple who began the study with high satisfaction, a 20point decline may reflect a major shift in marital quality. Future studies can address these sample problems by including more couples, or perhaps by focusing on newlywed couples, who tend to have uniformly high initial satisfaction and substantial variation in the degree and direction of change over time (Karney \& Bradbury, 1997).

Another limitation of the study is that positivity, negativity, and avoidance at baseline are not the only factors that could influence marital satisfaction over time. Competing explanations for changes in marital satisfaction include personality characteristics, changes in financial status, or the introduction of a child. Because these factors were not measured, their influence on results remains unknown. Using different methodologies to describe the longitudinal associations of baseline behavior and marital satisfaction is a valuable contribution. However, our explanations for how behavior and satisfaction interact with each other over time and how other variables influence this system are limited owing to the fact that we did not have Time 2 behavioral data and other contextual information. To permit a more complete set of explanations, future studies may want to collect several waves of behavioral data and to measure a number of environmental and personality factors that may play a role in marital satisfaction over time.

A complete understanding of the impact of couples' communication strategies would also require analyses, not feasible in the current study, of the specific issues chosen for problem-solving discussion. For example, it has been shown that a spouse's reaction to a discussion depends to some extent on whether the spouse desires change in the area being discussed (Heavey et al., 1995). In a similar vein, there may be variation in spouses' approaches to, expectations from, and reactions to discussions depending upon whether the area being discussed is one in which change is easy to accomplish (e.g., completing chores in a more timely fashion) or rather difficult to accomplish (e.g., increasing family income or adjusting to a new child).

As in most studies of the current type, there are limitations in the theoretical models employed to contextualize and interpret results. The predictions made by the "negative confrontation" and "social learning" models regarding the impact of "positive," "negative," and "avoidant" behaviors do not adequately account for the complex interactions between the type of communication used and variables that may moderate the effects of such communication on marital satisfaction (such as type of issues being discussed, the gender of the spouse advocating the change, the gender of the spouse communicating, etc.). Moreover, the broad communication categories of "positive," "negative," and "avoidant" behavior may overlook important distinctions within these categories.

For example, among "negative" behaviors, expressions of contempt, partner-focused hostility, or rage (unfocussed or outof-control anger) might be considerably more detrimental to marriages than expressions of dissatisfaction, frustration, or anger directed at specific behaviors. Likewise, among avoidant behaviors, ignoring a partner's attempts to communicate constructively may be different from ignoring a partner's generalized complaints that can 
be attributed to his or her temporary bad mood. Future studies aiming to clarify the impact of communication strategies on marital satisfaction might wish to separate out different types of negative and avoidant behaviors and to pay more attention to the content and context of problems being discussed.

\section{Conclusions}

The current study has made some theoretical progress by adding weight to the evidence supporting a social learning model over a negative confrontation model for predicting the longitudinal effects of communication on marital satisfaction. In particular, both husbands' and wives' negativity predicted declines in wives' satisfaction, and neither spouse's negativity produced improvement in husbands' satisfaction. In addition, both husbands' and wives' positivity predicted improvements in wives' satisfaction.

Although the sample had some limitations, confidence in these theoretical findings was increased because they were supported by two observational systems and two statistical methods. The story is complicated, however, by the fact that social learning predictions were supported only for wives, who reported greater changes in marital satisfaction than did husbands. Gender differences in marital satisfaction and in sensitivity to spousal communication are important issues for future study. In the husbands' data, there were two sign reversals between Time 1 associations and longitudinal associations. For instance, husbands' satisfaction shifted from a negative to a positive association with avoidance. These reversals did not generalize across systems or methods and may be an artifact of the study's design and statistics. Analysis using hierarchical linear modeling might help avoid such reversals if they are artifactual (Karney \& Bradbury, 1997; Rogossa, 1988). However, the possibility that some of the reversals represent real processes that occur in certain marital situations may warrant further consideration.
Methodological progress was also made by comparing two observational systems and two statistical methods. For the most part, a global rating system and a microanalytic coding system provided similar results, particularly for the level of overall positivity and negativity in the interaction. These global indices of positivity and negativity are commonly used in the marital literature, so it is reassuring to know that they can be similarly assessed with two very different behavioral observation systems. Moreover, because the RCRS method required less time than the VTCS system for training observers and completing ratings, future researchers looking broadly at positivity and negativity might be more inclined to choose this type of global rating system over a microlevel system.

Although the two statistical methods used here provide quite different ap. proaches to the problem of prediction, they generated similar results in many cases. We can have greater confidence in our findings when there is convergence across methods. Unlike the use of multiple observational systems, which is expensive and time-consuming, researchers can easily employ multiple statistical methods. We would therefore encourage future prediction studies of this type to incorporate both statistical methods. Direct comparison of these traditional methods with newer HLM methodology is also warranted.

This study has helped to settle some existing questions in the literature about the value of negative confrontation and differences among different statistical and observational methods. At the same time, the discussion of results raised a number of important issues, such as refining observational systems and theories to address subcategories of behavior within "negativity" and "avoidance" and integrating moderating variables into study designs and hypotheses. Do all roads really lead to Rome? The different methodological roads taken in this study led to the same general destination, while offering several interesting detours that warrant further exploration. 


\section{References}

Bradbury, T., \& Fincham, F. (1992). Attributions and behavior in marital interaction. Journal of Personality and Social Psychology, 63, 613-628.

Bradbury, T. N., Campbell, S. M., \& Fincham, F. D. (1995). Longitudinal and behavioral analysis of masculinity and femininity in marriage. Journal of Personality and Social Psychology, 68, 328-341.

Bradbury, T. N., \& Fincham, F. D. (1991). A contextual model for advancing the study of marital interaction. In G. Fletcher \& F. Fincham (Eds.), Cognition in close relationships (pp. 127-147). Hillsdale, NJ: Erlbaum.

Bradbury, T. N., \& Karney, B. R. (1993). Longitudinal study of marital interaction and dysfunction: Review and analysis. Clinical Psychology Review, 13, 15-27.

Bradbury, T. N., \& Karney, B. R. (1996). Assessing the longitudinal effects in marital research: A simulation study comparing three approaches. Manuscript in preparation.

Byrk, A., \& Raudenbush, S. (1992). Hierarchical linear models: Applications and data analysis methods. Newbury Park, CA: Sage.

Christensen, A., \& Arrington, A. (1987). Research issues and strategies. In T. Jacob (Ed.), Family interaction and psychopathology: Theories, methods and findings (pp. 259-296). New York: Plenum Press.

Christensen, A., \& Heavey, C. L. (1990). Gender and social structure in the demand/withdraw pattern of marital interaction. Journal of Personality and Social Psychology, 59, 73-81.

Christensen, A., \& Pasch, L. (1993). The sequence of marital conflict: An analysis of seven phases of marital conflict in distressed and nondistressed couples. Clinical Psychology Review, 13, 1-14.

Christensen, A., \& Sullaway, M. (1984). Communication Patterns Questionnaire. Unpublished Manuscript, University of California, Los Angeles.

Cohan, C., \& Bradbury, T. (1997). Negative life events, marital interaction, and the longitudinal course of newlywed marriage. Journal of Personality and Social Psychology, 73, 114-128.

Crowther, J. H. (1985). The relationship between depression and marital adjustment: A descriptive study. The Journal of Nervous and Mental Disease, $173,227-231$.

Filsinger, E. E., \& Thoma, S. J. (1988). Behavioral antecedents of relationship stability and adjustment: A five-year longitudinal study. Journal of Marriage and the Family, 50, 785-795.

Geiss, S. K., \& O'Leary, K. D. (1981). Therapist ratings of frequency and severity of marital problems: Implications for research. Journal of Marital and Family Therapy, 7, 515-520.

Gottman, J. M. (1993). A theory of marital dissolution and stability. Journal of Family Psychology, 7, $57-75$.

Gottman, J. M., \& Krokoff, L. J. (1989). Marital interaction and satisfaction: A longitudinal view. Journal of Consulting and Clinical Psychology, 57, $47-52$.

Gottman, J. M., \& Krokoff, L. J. (1990). Complex statistics are not always clearer than simple statistics: A reply to Woody and Costanzo. Journal of Consulting and Clinical Psychology, 58, 502-505.
Heavey, C. L., Christensen, A., \& Malamuth, N. M. (1995). The longitudinal impact of demand and withdrawal during marital conflict. Journal of Consulting and Clinical Psychology, 63, 797-801.

Heavey, C. L., Layne, C., \& Christensen, A. (1993) Gender and conflict structure in marital interaction: A replication and extension. Journal of Clinical and Counseling Psychology, 61, 16-27.

Huston, T. L., \& Vangelisti, A. L. (1991). Socioemotional behavior and satisfaction in marital relationships: A longitudinal study. Journal of Personality and Social Psychology, 61, 721-733.

Jacobson, N. (1989). The politics of intimacy. The $B e-$ havior Therapist, 12, 29-32.

Jacobson, N., \& Margolin, G. (1979). Marital therapy. New York: Brunner/Mazel.

Jacobson, N. S., Waldron, H., \& Moore, D. (1980). Toward a behavioral profile of marital distress. Journal of Consulting and Clinical Psychology, 48, 696-703.

Julien, D., Markman, H. J., \& Lindahl, K. M. (1989). A comparison of a global and a microanalytic coding system: Implications for future trends in studyjng interactions. Behavioral Assessment, 11, 81-100.

Karney, B., \& Bradbury, T. (1997). Neuroticism, marital interaction, and the trajectory of marital satisfaction. Journal of Personality and Social Psychology, 72, 1075-1092.

Karney, B. R., \& Bradbury, T. N. (1995). The longitudinal course of marital quality and stability: A review of theory, methods, and research. Psychological Bulletin, 118, 3-34.

Katz, L. F., \& Gottman, J. M. (1993). Patterns of marital conflict predict children's internalizing and externalizing behavior. Developmental Psychology, 29, $940-950$

Locke, H. J., \& Wallace, K. M. (1959). Short marital adjustment and prediction tests: Their reliability and validity. Marriage and Family Living, 21, 251255.

Noller, P., Feeney, J. A., Bonnell, D., \& Callan, V. J. (1994). A longitudinal study of conflict in early marriage. Journal of Social and Personal Relationships, 11, 233-252.

Rankin-Esquer, L., Baucom, D., Christensen, A., Epstein, N., Burnett, C., et al. (1998). Communication Patterns Questionnaire: Discriminating between community, clinic and divorcing couples. Unpublished manuscript.

Raush, H. L., Barry, W. A., Hertel, R. K., \& Swain, M. A. (1974). Communication, conflict, and marriage. San Francisco: Jossey-Bass.

Rogossa, D. (1988). Myths about longitudinal research. In K. Schale, R. Campbell, W. Merideth, \& S. Rawlings (Eds.), Methodological issues in aging research (pp. 171-209). New York: Springer.

Rosenthal, R. (1982). Conducting judgment studies. In K. Scherer \& P. Eckman (Eds.), Handbook of methods in nonverbal behavior research. New York: Cambridge University Press.

Sillars, A., Pike, G., Jones, T., \& Murphy, M. (1984). Communication and understanding in marriage. Human Communication Research, 10, 317-350.

Sillars, A.L.(1981). Attributions and interpersonal conflict resolution. In J. Harvey, W. J. Ickes, R. F. Kidd 
(Eds.), New directions in attribution research (Vol. 3). Hillsdale, NJ: Erlbaum.

Smith, D. A., Vivian, D., \& O'Leary, D. (1991). The misnomer proposition: A critical reappraisal of the longitudinal status of negativity in marital communication. Behavioral Assessment, 13, 7-24.

Smith, D. A., Vivian, D., \& O'Leary, K. D. (1990). Longitudinal prediction of marital discord from pre- marital expressions of affect. Journal of Consulting and Clinical Psychology, 58, 790-798.

Stuart, R. B. (1980). Helping couples change. New York: Guilford Press.

Woody, E. Z., \& Costanzo, P. R. (1990). Does marital agony precede marital ecstasy? A comment on Gottman and Krokoff's "Marital interaction and satisfaction: A longitudinal view." Journal of Consulting and Clinical Psychology, 58, 499-501. 